\title{
Klasifikasi Diabetic Retinopathy Berbasis Pengolahan Citra Fundus dan Deep Learning
}

\section{Diabetic Retinopathy Classification Based on Fundus Image Processing and Deep Learning}

\author{
Syafiq Hilmi Abdullah1)*, Rita Magdalena 2 ), \& R Yunendah Nur Fu'adah ${ }^{3)}$ \\ 1)Teknik Telekomunikasi, Fakultas Teknik Elektro, Universitas Telkom, Indonesia \\ 2) Teknik Telekomunikasi, Fakultas Teknik Elektro, Universitas Telkom, Indonesia \\ 3) Teknik Telekomunikasi, Fakultas Teknik Elektro, Universitas Telkom, Indonesia
}

*Coresponding Email: syafiq.hilmi@gmail.com

\section{Abstrak}

Retinopati Diabetik merupakan salah satu penyakit pada retina mata yang disebabkan oleh adanya komplikasi pada penyakit diabetes di mana terdapat kerusakan pembuluh darah pada retina sehingga mengalami penumpukan cairan (eksudat) serta pendarahan pada retina. Pemeriksaan medis untuk mendeteksi penyakit retinopati diabetik membutuhkan waktu yang relatif lama karena dilakukan secara manual oleh dokter dengan mengamati citra fundus dari retina pasien, namun citra fundus retina tidak dapat memberikan informasi secara jelas. Oleh karena itu, dilakukan perancangan sistem Convolutional Neural Network (CNN) menggunakan model EfficientNet untuk melakukan klasifikasi dengan waktu yang efektif dan efisien. Dataset yang digunakan adalah APTOS 2019 Blindness Detection berisi 3662 citra RGB yang terbagi dalam 5 kelas, yaitu No DR, mild NPDR, moderate NPDR, severe NPDR, dan proliferate DR. Hasil akhir menunjukkan model terbaik menggunakan optimizer AdaMax, learning rate 0.001, dan batch size 32 dengan akurasi sebesar $82.096 \%$, nilai presisi sebesar 67.6\%, nilai recall sebesar 63.4\%, dan $f-1$ score sebesar $64.6 \%$. Berdasarkan hasil penelitian, kinerja sistem menunjukkan bahwa model yang dibuat dapat dijadikan sistem deteksi dini serta mengurangi waktu pemeriksaan medis pada pasien penyakit Retinopati Diabetik.

Kata kunci: Convolutional Neural Network (CNN), EfficientNet, Retinopati Diabetik

\begin{abstract}
Diabetic retinopathy is a disease of the retina of the eye caused by complications in diabetes where there is damage to blood vessels in the retina so that fluid buildup (exudate) and retinal bleeding occur. Medical examination to detect diabetic retinopathy takes a relatively long time because it is done manually by the doctor by observing the fundus image of the patient's retina, but the retinal fundus image cannot provide clear information. Therefore, a Convolutional Neural Network (CNN) system was designed using the EfficientNet model to classify in an effective and efficient manner. The dataset used is APTOS 2019 Blindness Detection containing 3662 RGB images divided into 5 classes, namely No DR, mild NPDR, moderate NPDR, severe NPDR, and proliferate DR. The results show the best model using the AdaMax optimizer, 0.001 learning rate, and 32 batch size with $82.096 \%$ accuracy, $67.6 \%$ precision, $63.4 \%$ recall, and an $f-1$ score of $64.6 \%$. Based on the results, the performance of the system showed that the model can be used as an early detection system and help reduce the time of medical examination required for Diabetic Retinopathy disease. Keywords: Convolutional Neural Network (CNN), Diabetic Retinopathy, EfficientNet.
\end{abstract}

How to Cite: Abdullah, S. H, Magdalena, R, Fu'adah, R. Y. N. (2022). Klasifikasi Diabetic Retinopathy Berbasis Pengolahan Citra Fundus dan Deep Learning. JESCE (Journal of Electrical and System Control Engineering). 5 (2): 84-90 


\section{PENDAHULUAN}

Retinopati diabetik disebabkan oleh adanya komplikasi pada penyakit diabetes (Zainet, 2020). Salah satu penyebab utama kebutaan dan gangguan pada penglihatan disebabkan oleh retinopati diabetik. Pada tahun 2010 dari keseluruhan 32,4 juta tuna netra dan 191 juta penderita gangguan penglihatan, 0,8 juta mengalami kebutaan dan 3,7 juta mengalami gangguan akibat retinopati diabetik. Retinopati diabetik memiliki gejala seperti microaneurysm, adanya kebocoran pada pembuluh darah, terjadinya pembengkakan pada retina, tumbuhnya pembuluh darah baru secara abnormal, dan adanya kerusakan pada jaringan saraf (Kurniawan, 2015). Namun gejala pada retinopati diabetik sulit untuk dideteksi secara kasat mata, sehingga diperlukan citra fundus untuk memudahkan identifikasi. Proses identifikasi tersebut membutuhkan waktu yang relatif lama, sehingga diperlukan sebuah sistem untuk membantu menganalisis dan mengklasifikasi penyakit retinopati diabetik. Berdasarkan tingkat keparahannya retinopati diabetik dibagi menjadi dua kelompok yaitu nonproliferatif dan proliferatif sebagai tahap lanjutan (Dewi, 2019).

Convolutional Neural Network (CNN) merupakan variasi artificial neural network yang memiliki bobot dan beberapa hidden layer yang disusun menjadi sebuah arsitektur (Handono, 2020). CNN merupakan bagian dari deep learning, yang merupakan konsep machine learning dengan metode untuk mendeteksi fitur citra data berdasarkan kemampuan jaringan saraf tiruan dan menggunakan algoritma dalam melakukan proses pada lapisan untuk menghasilkan output yang lebih akurat.

CNN terbagi menjadi dua bagian yaitu feature extraction yang berisi convolutional layer, pooling layer, dan aktivasi RelU serta classification layer yang berisi fully connected layer, fungsi flatten, dan fungsi aktivasi (Taweh, 2017).

Sebelumnya telah dilakukan berbagai penelitian untuk melakukan klasifikasi penyakit diabetic retinopathy menggunakan CNN, beberapa di antaranya yang berjudul Modified Alexnet Architecture for Classification of Diabetic (Shanti, dkk., 2019) menggunakan dataset Messidor yang berisi citra fundus berwarna. Hasil penelitian menunjukkan dari 303 citra yang di validasi coba didapatkan akurasi sebesar 96.25\% menggunakan arsitektur Alexnet yang telah di modifikasi. Selanjutnya penelitian yang berjudul Comparative Analysis of Deep Learning Methods of Detection of Diabetic Retinopathy (Park, dkk., 2020) yang membandingkan klasifikasi 5 kelas retinopati diabetik oleh 3 model CNN yaitu DenseNet, ResNet, dan EfficientNet dengan akurasi untuk model EfficientNet sebesar $65.5 \%$ untuk data asli dan 79\% dengan preprocessing CLAHE dan augmentasi data. Selanjutnya penelitian yang berjudul Deep Learning untuk Klasifikasi Diabetic Retinopathy menggunakan model EfficientNet (Syamsul, dkk., 2020) yang menggunakan dataset APTOS 2019 Blindness Detection berisi 3662 citra berwarna untuk klasifikasi 5 kelas retinopati diabetik dengan akurasi sebesar 75\% untuk data asli dan 79.8\% setelah melalui proses CLAHE.

Berdasarkan penelitian-penelitian 
sebelumnya, pada penelitian ini dibuat sistem klasifikasi retinopati diabetik dengan menggunakan metode Convolutional Neural Network (CNN) dengan menggunakan model EfficientNet-B0 untuk mendeteksi dan mengklasifikasi penyakit retinopati diabetik sebanyak lima kelas yaitu No $D R$, Mild Non-Proliferative Diabetic Retinopathy, Moderate Non-Proliferative Diabetic Retinopathy, Severe NonProliferative Diabetic Retinopathy, dan Proliferate Diabetic Retinopathy.

\section{METODE PENELITIAN}

Tujuan dari penelitian ini adalah mengimplementasikan sistem yang dapat mengklasifikasikan penyakit retinopati diabetik ke dalam 5 kelas menggunakan CNN dengan model EfficientNet serta menganalisis parameter yang memengaruhi performansi metode CNN dengan model EfficientNet.

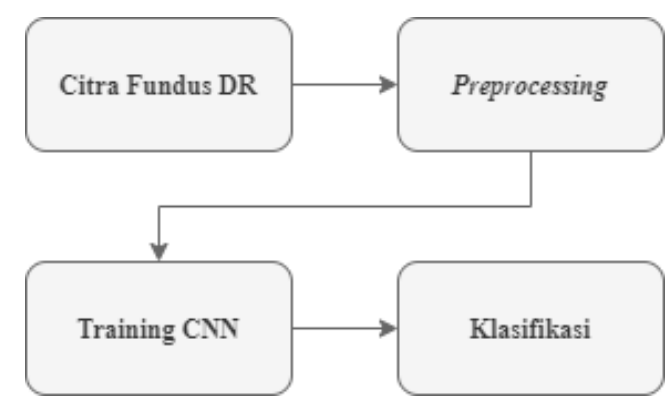

Gambar 1. Blok Diagram Sistem Klasifikasi

Gambar 1 menunjukkan perancangan sistem dari penelitian ini. Input sistem yang digunakan adalah citra fundus dari penyakit retinopati diabetik yang dilakukan klasifikasi. Selanjutnya dilakukan preprocessing dengan proses resize terhadap citra untuk menyamakan ukuran citra yang berbeda-beda. Selanjutnya pelatihan model dilakukan dengan memberikan data latih kepada sistem dengan tujuan agar mendapatkan hasil klasifikasi yang maksimal. Klasifikasi merupakan keluaran pelatihan model dalam mengenali objek untuk diklasifikasi sesuai dengan kelas yang telah ditentukan. Pada tahapan ini sistem menggunakan EfficientNet-B0 untuk pemrosesan hingga mendapatkan hasil yang diinginkan.

Gambar 2. Usulan Model EfficientNet

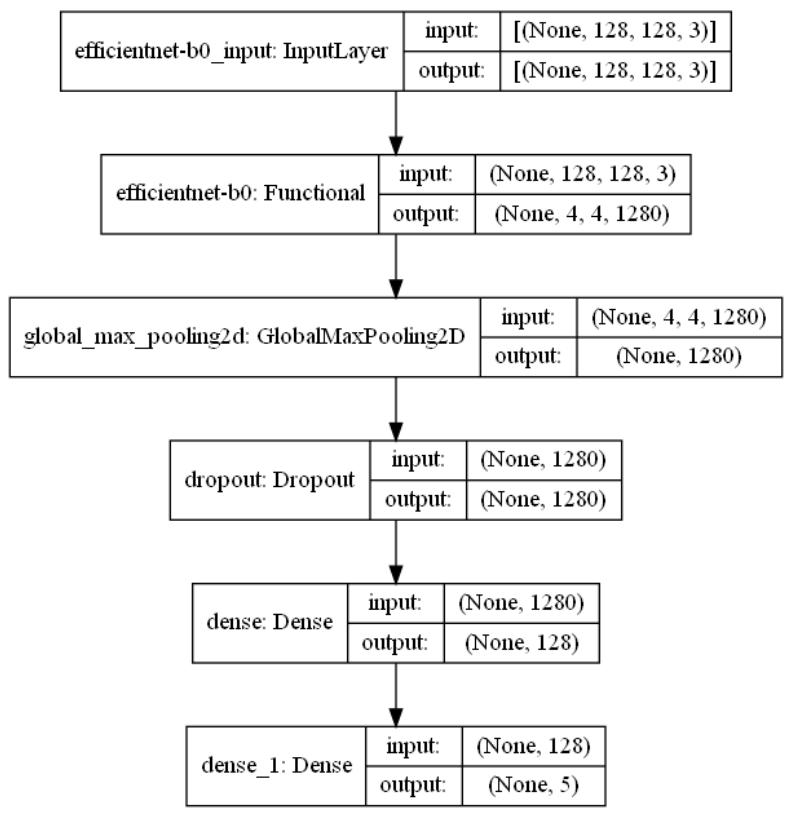

Gambar 2 menunjukkan usulan model EfficientNet yang digunakan untuk penelitian. Pada blok EfficientNet terdapat layer yang berisi CNN. Sebagian besar proses komputasi pada sistem terjadi pada lapisan konvolusional dan merupakan layer pertama yang dilewati setelah input gambar, pada layer ini terdapat filter yang dapat memindai bagian gambar. Pooling layer mengambil feature map yang dihasilkan convolutional layer serta melakukan pengurangan dimensi secara efektif sehingga mengurangi kompleksitas model. Kemudian RelU layer bekerja sebagai fungsi aktivasi yang membuat semua nilai piksel yang bernilai negatif 
menjadi nol untuk membantu menguraikan feature map menjadi lebih dekat dengan gambar yang terkait. Citra multidimensi kemudian diubah menjadi 1 dimensi oleh flatten sebagai masukan untuk fully connected layer, setiap neuron pada lapisan ini terhubung ke semua aktivitas pada lapisan sebelumnya. Kemudian fungsi softmax akan menghitung probabilitas setiap kelas untuk kemudian menjadikan kelas dengan probabilitas tertinggi sebagai hasil prediksi untuk klasifikasi 5 kelas diabetic retinopathy.

\section{HASIL DAN PEMBAHASAN}

Pengujian dilakukan dengan membagi data menjadi 2746 data latih dan 916 data validasi. Pengujian dilakukan untuk menguji pengaruh jenis optimizer, pengaruh nilai learning rate, dan pengaruh nilai batch size terhadap performansi sistem dengan mencari nilai akurasi, loss, precision, recall, dan f1score.

Tabel 1. Hasil Pengujian Optimizer

\begin{tabular}{ccc}
\hline Optimizer & $\begin{array}{c}\text { Akurasi } \\
\text { (\%) }\end{array}$ & Loss \\
\hline SGD & 79.913 & 0.6295 \\
\hline RMSprop & 81.332 & 2.4586 \\
\hline Adam & 81.878 & 0.7109 \\
\hline Adamax & 82.096 & 0.9770 \\
\hline Nadam & 80.677 & 0.9661 \\
\hline
\end{tabular}

Pada skenario pertama dilakukan pengujian untuk mengetahui pengaruh perbedaan jenis optimizer pada sistem. Pengujian menggunakan ukuran citra 128x128 piksel, iterasi sebanyak 50 epoch dengan early stopping, learning rate 0.001 , dan batch size 32 . Hasil pengujian menunjukkan optimizer terbaik untuk sistem menggunakan optimizer Adamax dengan validasi akurasi sebesar $82.096 \%$ dan loss sebesar 0.977. Hal ini dikarenakan optimizer Adamax melakukan pembaruan parameter momentum dari optimizer sebelumnya, sehingga mempercepat proses optimasi dan menghasilkan optimasi yang lebih efektif.

Tabel 2. Hasil Pengujian Learning Rate

\begin{tabular}{ccc}
\hline $\begin{array}{c}\text { Learning } \\
\text { Rate }\end{array}$ & $\begin{array}{c}\text { Akurasi } \\
\text { (\%) }\end{array}$ & Loss \\
\hline 0.1 & 49.563 & 1.3048 \\
\hline 0.01 & 78.38 & 0.7163 \\
\hline 0.001 & 82.096 & 0.9770 \\
\hline 0.0001 & 79.367 & 0.7094 \\
\hline
\end{tabular}

Skenario kedua dilakukan pengujian untuk mengetahui pengaruh nilai learning rate pada sistem. Pengujian menggunakan ukuran citra 128x128 piksel, iterasi sebanyak 50 epoch dengan early stopping, optimizer Adamax, dan batch size 32. Hasil pengujian menunjukkan nilai learning rate terbaik untuk sistem menggunakan learning rate 0.001 dengan nilai validasi akurasi sebesar $82.096 \%$ dan loss sebesar 0.977 . Hal ini dikarenakan penggunaan nilai learning rate yang kecil menyebabkan sistem semakin teliti dalam melakukan pelatihan serta klasifikasi, sehingga performansi yang dihasilkan lebih baik dibandingkan dengan penggunaan nilai learning rate yang lebih besar. Namun, learning rate yang terlalu kecil dapat menyebabkan proses pengujian yang terlalu lama dan dapat macet, sedangkan nilai yang terlalu besar dapat menyebabkan pembelajaran yang kurang optimal karena terlalu cepat dan proses pelatihan tidak stabil.

Skenario ketiga dilakukan pengujian untuk mengetahui pengaruh batch size 
pada sistem. Pengujian menggunakan ukuran citra $128 \times 128$ piksel, iterasi sebanyak 50 epoch dengan early stopping, optimizer Adamax, dan learning rate 0.001 . Hasil pengujian menunjukkan nilai batch size terbaik untuk sistem menggunakan batch size 32 dengan nilai validasi akurasi sebesar 82.096\% dan loss sebesar 0.977. Hal ini dikarenakan batch size yang lebih kecil memiliki kecepatan konvergensi dalam algoritma yang lebih cepat namun menghasilkan noise dalam perhitungan yang lebih besar, sedangkan penggunaan batch size yang besar membantu mengurangi noise namun tidak menjamin adanya peningkatan pada akurasi.

\begin{tabular}{ccc}
\multicolumn{3}{c}{ Tabel 3. H asil Pengujian Batch Size } \\
\hline Batch Size & $\begin{array}{c}\text { Akurasi } \\
\text { (\%) }\end{array}$ & Loss \\
\hline $\mathbf{8}$ & 81.004 & 0.7125 \\
\hline $\mathbf{1 6}$ & 81.223 & 0.8219 \\
\hline $\mathbf{3 2}$ & 82.096 & 0.9770 \\
\hline $\mathbf{6 4}$ & 79.367 & 0.9381
\end{tabular}

Hasil pengujian seluruh skenario menunjukkan model terbaik pada sistem adalah menggunakan optimizer Adamax, learning rate 0.001, dan batch size 32 .

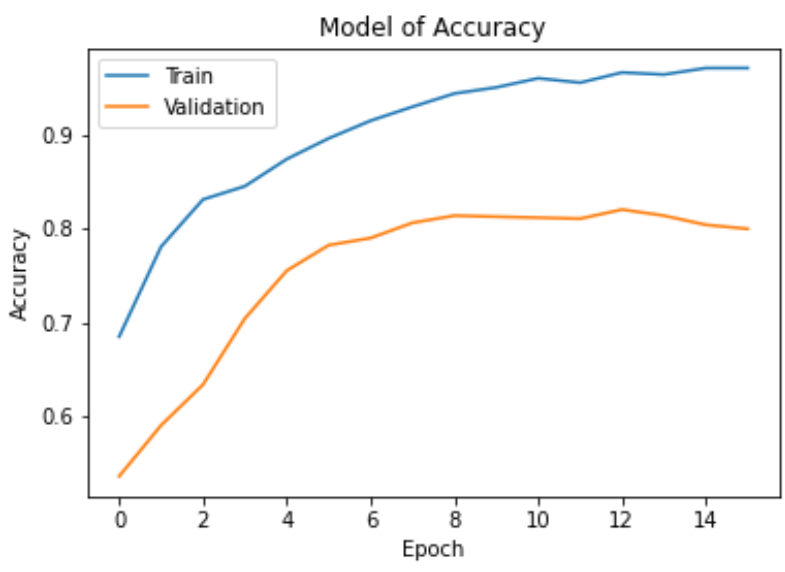

Gambar 3. Grafik Akurasi Pengujian Terbaik

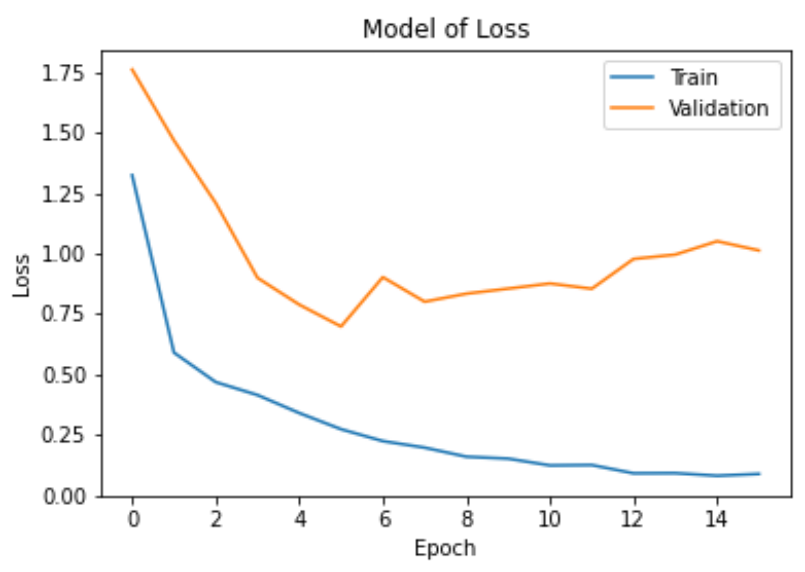

Gambar 4. Grafik Loss Pengujian Terbaik

Tabel 4. Classification Report Pengujian Terbaik

\begin{tabular}{ccccc}
\hline Kelas & $\begin{array}{c}\text { Presisi } \\
(\%)\end{array}$ & $\begin{array}{c}\text { Recall } \\
(\%)\end{array}$ & $\begin{array}{c}\text { F1- } \\
\text { score } \\
(\%)\end{array}$ & $\begin{array}{c}\text { Jumlah } \\
\text { Gambar }\end{array}$ \\
\hline No DR & 98 & 98 & 98 & 454 \\
\hline Mild & 57 & 60 & 58 & 84 \\
\hline Moderate & 73 & 83 & 78 & 241 \\
\hline Severe & 38 & 33 & 35 & 49 \\
\hline Proliferate & 72 & 43 & 54 & 88
\end{tabular}

\begin{tabular}{lllll} 
Total & 67.6 & 63.4 & 64.6 & 916 \\
\hline
\end{tabular}

Gambar 3 dan Gambar 4 menunjukkan grafik akurasi dan grafik loss pada hasil pengujian menggunakan parameter terbaik. Terlihat bahwa nilai akurasi dan loss data validasi dan data training terdapat gap yang besar. Hal ini berarti bahwa masih terjadi overfitting pada sistem. Selain itu, parameter lain untuk mengukur performansi model juga dapat dilihat pada nilai presisi, recall, dan $f 1$ score. Tabel 4 menunjukkan bahwa nilai presisi, recall, dan f1-score pada kelas mild, severe, dan proliferate cukup rendah dibandingkan dengan kelas no $D R$ dan moderate. Hal ini terjadi karena tidak meratanya jumlah gambar setiap kelas yang menyebabkan overfitting. 


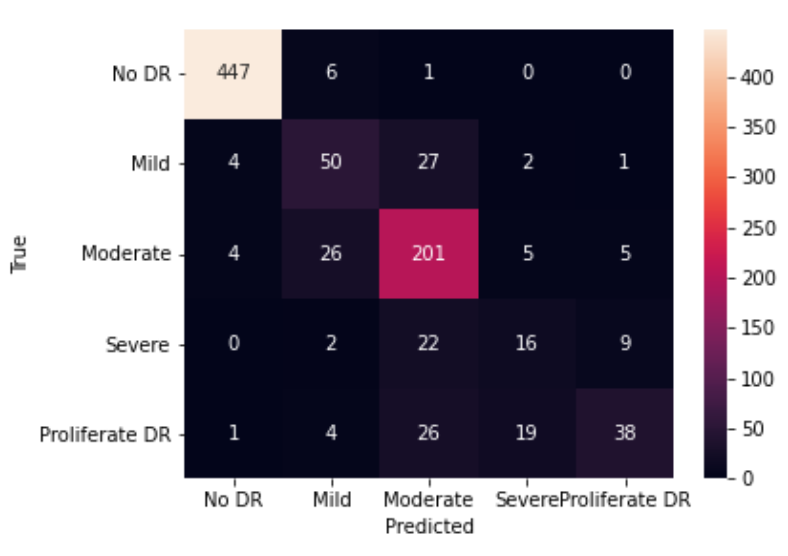

Gambar 5. Confusion Matrix Pengujian Terbaik

Gambar 5 menunjukkan bahwa dari total 916 citra yang digunakan sebagai data validasi, terdapat 752 citra yang terdeteksi secara benar sesuai dengan kelasnya, yang berarti masih banyak prediksi yang tidak sesuai antara prediksi dengan data aktual.

\section{SIMPULAN}

Penelitian ini telah merancang sistem untuk klasifikasi 5 kelas penyakit retinopati diabetik menggunakan CNN dengan model EfficientNet-B0 dan memperoleh hasil akurasi sebesar 82.096\%, dengan nilai presisi sebesar $67.6 \%$, nilai recall sebesar $63.4 \%$, dan $f-1$ score sebesar $64.6 \%$ yang dicapai menggunakan optimizer AdaMax, learning rate 0.001 , dan batch size 32 .

Untuk penelitian lebih lanjut, disarankan menggunakan jumlah gambar yang seimbang untuk setiap kelas untuk mengurangi kemungkinan overfitting pada sistem. Kemudian diperlukan metode preprocessing pada citra untuk meningkatkan kualitas citra agar sistem lebih mudah dalam melakukan klasifikasi ciri pada penyakit retinopati diabetik.

\section{DAFTAR PUSTAKA}

Association, A.D., et al. 2014. Diagnosis and Classification of Diabetes Mellitus. Diabetes care. 37(1): S81-S90.

Dewi, I.R., Magdalena, R. \& Fu'adah, R.Y.N. 2019. Klasifikasi Retinopati Dibaetik pada Citra Mata Digital menggunakan 3D GLCM dengan Learning Vector Quantization. eProceedings of Engineering. 6(2).

Fu'adah, R.Y.N., Sa'idah, S., Wijayanto, I., Ibrahim, N. and Magdalena, R. 2021. Computer Aided Diagnosis for Early Detection of Glaucoma Using Convolutional Neural Network (CNN). Proceedings of the 1st International Conference on Electronics, Biomedical Engineering, and Health Informatics. 467-475.

Handono, S.F., Anggraeny F.T. \& Rahmat, B. 2020. Implementasi Convolutional Neural Network (CNN) untuk Deteksi Retinopati Diabetik. Jurnal Informatika dan Sistem Informasi (JIFoSI). 1(1): 672.

Kurniawan, Y.S. 2015. Deteksi dan Klasifikasi Tingkat Keparahan Retinopati Diabetes dengan menggunakan Metode Klasifikasi K-Nearest Neighbour. eProceedings of Engineering. 2(1).

Park, A., Ziyaden, A., Tukeshev, K., Jaxylykova, A. \& Abdullina, D. 2020. Comparative Analysis of Deep Learning Methods of Detection of Diabetic Retinopathy. Cogent Engineering. $7(1)$.

Rizal, S., Ibrahim, N., Pratiwi, N.K.C., Saidah, S. \& Fu'adah, R. Y. N. 2020. Deep Learning untuk Klasifikasi Diabetic Retinopathy menggunakan model EfficientNet. Jurnal Teknik Energi Elektrik, Teknik Telekomunikasi, \& Teknik Elektronika. 8(3): 693-705.

Sarirotul, I. \& Agung, N. 2018. Implementasi Deep Learning pada Identifikasi Jenis Tumbuhan berdasarkan Citra Daun menggunakan Convolutional Neural Network. JUSTINDO (Jurnal Sistem \& Teknologi Informasi Indonesia. 3(2): 4956.

Shanti, T. \& Sabeenian, R.S. 2019. Modified Alexnet Architecture for Classification of Diabetic. Computers and Electrical Engineering. 76: 56-64.

Tan, M. \& Le, Q.V. 2019. Efficientnet: Improving Accuracy and Efficiency through AutoML and Model Scaling. Diunduh di https://ai.googleblog.com/2019/05/effici entnet-improving-accuracy-and.html tanggal 12 Juni 2021.

Tan, M. \& Le, Q.V. 2019. Efficientnet: Rethinking 
Model Scaling for Convolutional Neural Networks. International Conference on Machine Learning.

Taweh, B.I.. 2017. Introduction to Deep Learning using R. Apress, San Fransisco, California, USA.

Vaughan, D.G., Asbury, T., Paul, R.E. \& John, P.W. 2014. Oftalmologi Umum. Edisi 17. Penerbit Buku Kedokteran.

Wikipedia. Retina. Diunduh di https://en.wikipedia.org/wiki/Retina tanggal 17 November 2020.

Zainet, A., Magdalena, R. \& Raharjo, J. 2020. Klasifikasi Non-Proliferative Diabetic Retinopathy (NPDR) melalui Citra Iris Mata menggunakan Metode Fraktal dengan Jaringan Syaraf Tiruan (JST). Seminar Nasional Teknologi Informasi dan Komunikasi. 3(1): 503-509. 